\title{
It's Now or Never! Future Discounting in the Application of the Online Privacy Calculus
}

\author{
Marco Lünich, Frank Marcinkowski, \& Kimon Kieslich \\ Department of Social Sciences, Heinrich Heine University Düsseldorf, Düsseldorf, Germany
}

\begin{abstract}
Many people engage in extensive use of networked digital systems despite concerns over their privacy, a phenomenon called the "online privacy paradox." Although privacy calculus research has argued that the benefits of usage usually outweigh the expected privacy losses, it is unclear why people come to this conclusion. We argue that users treat decisions about digital media use as intertemporal choices; that is, they mentally shift into the future the potential damage connected with risk-taking while being convinced of the immediate enjoyment of the benefits of technology use. An online survey conducted among German users for three use cases-e-commerce, online political participation, and self-tracking-indicated that users expect benefits to materialize earlier than associated costs and that the earlier the benefits occur, the higher the amount of benefits users expect. The expected time of the occurrence of benefits and risks explains digital media use in addition to cost-benefit calculations, suggesting a time-discounting bias.
\end{abstract}

Keywords: Privacy calculus model; intertemporal choices; time discounting; perceptual bias; online political participation; self-tracking; e-commerce

\section{Introduction}

We are living in an age in which nearly all internet users should be aware of the risks that the use of digital technologies poses to their informational privacy. For instance, when using social media and other digital applications, users actively disclose their thoughts, emotions, and other personal information, doing so involuntarily by leaving digital traces-so-called metadata-of their online activity. Each mouse click and push of a keyboard button can be recorded and stored (and often will be) and might consequently be subject to unforeseen analyses by corporations, state agencies, and hackers. Analyses of personal information give direct insights into the behavior, attitudes, and preferences of online users and pose severe threats to their informational privacy, such that data may be exploited to the disadvantage of users (e.g., by individually adjusting prices, personalizing media services, etc.). Users are increasingly aware that their private information may fall into the wrong hands and that their privacy may be compromised (Acquisti et al., 2015; Infratest dimap, 2018; Madden, 2014). Why, therefore, do online users express privacy concerns but continue and even extend their use of online applications, revealing their personal information in spite of the risks posed by third parties prying into their digital data? This puzzle-referred to as the online privacy paradox in the literature on online media usage-has been the subject of extensive research (Baruh et al., 2017; Kokolakis, 2017). In this paper, we investigate to what extent the predominant answer to this puzzle-i.e., the online privacy calculus, in which benefits and losses are weighed-is influenced by perceptions of the time of occurrence of benefits as well as losses, thus adding a factor of irrationality to the predominantly rational approach of the online privacy calculus. We emphasize that decisions about usage of digital online media may not be only a matter of rational-choice-based weighing of benefits and 
risks, but also dependent on the temporality of decisions; that is, expectations of benefits in the near term lead to perceptions of greater benefits, which in turn increase usage, while potential risks are shifted to the distant future, discounting potential losses.

Consequently, we report and discuss an empirical analysis of the extent to which perceptions of the perceived time of occurrence of risks and benefits directly and indirectly influence usage of online services that collect sensitive digital data. To answer our questions, we collected survey data for three distinct fields of online activity, that is, e-commerce, online political participation, and self-tracking, for which results are subsequently reported and discussed.

\section{The Online Privacy Calculus}

An explanation for the apparent inconsistency of privacy concerns and subsequent online behavior can be found in the privacy calculus model (Laufer \& Wolfe, 1977). The privacy calculus posits that when it comes to the perception of online users, the benefits of online media use clearly outweigh the associated privacy risks (Culnan \& Armstrong, 1999; Dienlin \& Metzger, 2016). In relation to social media, the privacy calculus is based primarily on conceptions of privacy management theory that address the competition between users' social need for selfdisclosure and their need to withhold intimate personal information (Krasnova et al., 2010; Petronio, 2002, 2010; Taddicken, 2014). Mirroring a cost-benefit calculation, the privacy calculus can be extended to all online applications that require users to hand over their personal data in return for products and services. As explained above, the utility of using online applications always comes with certain costs, including the misuse of personal information and the (potential) loss of privacy. The rational choice logic of the calculus posits that as soon as there is a surplus in perceived benefits from usage that outweighs the cons associated with the privacy risks, the resulting positive balance positively predicts intentions and usage behavior (Dienlin \& Metzger, 2016). The resulting surplus drives behavior that seems contradictory at first but appears to be rationally calculated and economically reasonable. However, various scholars have raised doubts about the simplicity of calculations regarding the use of online applications. Dienlin and Metzger (2016) introduced perceptions of privacy self-efficacy as an explanatory variable, in addition to the perceived benefits and costs that presumably drive social media use. They found that perceptions of higher privacy self-efficacy lead to increased self-withdrawal when it comes to the use of the social network site (SNS) Facebook. Likewise, in a study conducted by Hargittai and Marwick (2016), although teenage social media users indicated an awareness of the privacy risks associated with the use of social media, they also suggested that a perceived lack of control contributed to their risky behavior. When the majority of one's peers participate in social media, data protection appears to be cumbersome, data disclosure thus seems inevitable, and apathy consequently takes hold and distorts rational cost-benefit analysis. Coincidentally, theories of human action, such as the theory of planned behavior (Ajzen, 1991, 2002), not only include attitudinal and socionormative components as influences on the perceived favorability of behavior; they also introduce beliefs about corresponding control perceptions. In a study of Korean online users, Choi et al. (2018) conceptualized privacy fatigue, including privacy cynicism (Hoffmann et al., 2016), as an influential predictor of diminished control beliefs regarding online privacy behavior, which increase intentions to disclose information and drive disengagement in situations where personal data are misused.

Although such research sheds light on further influencing variables that need to be incorporated into the costbenefit analysis, the calculus model merely shifts the question in a new direction: Why do the majority of people regularly believe that the expected benefits of digital technologies outweigh their potential harm to privacy? Online privacy research has conceptually integrated the fallibilities and biases of human decision-making that call into question the existence of a purely rational cost-benefit analysis when making privacy decisions (Acquisti, 2004; Acquisti \& Grossklags, 2005; Wilson \& Valacich, 2012). However, there has been little empirical research on the online privacy paradox and the privacy calculus, which incorporates approaches from behavioral economics that address human decision-making under circumstances of incomplete information, bounded rationality, and perceptual bias (Barth \& de Jong, 2017; Gerber et al., 2018; Kokolakis, 2017). The important question here is not only what influences users' perceptions of costs and benefits but also how the calculation of costs and benefits takes place in the first place and whether deviations from rationality have additional explanatory value with respect to the online privacy paradox. Thus, we extend the line of research concerning the mainly rational privacy calculus model by adding factors to the equation that can be understood as human bias. We argue that, next to a rational calculation of benefits and risks, there are somewhat irrational factors which influence data disclosing usage of 
online applications in various domains. In this paper, based on the literature concerning intertemporal choices, we focus on temporal perceptions of consequences, namely, expectations of the occurrence of benefits and losses.

\section{Decisions About the Use of Digital Applications as Intertemporal Choices}

In many decision-making situations, people are forced to weigh the costs and benefits that arise at different points in time. This is the case, for example, with investments in one's own education: One first has to partake in training in order to be able to reap the profit at a later point in time (i.e., in the form of an increased salary). Economists describe such situations as intertemporal choices (Loewenstein et al., 2003), of which financial investments are the paradigmatic case. Such choices initially generate costs in the form of a renunciation of consumption, and these costs are offset by the prospect of increased profits in the future. Because most people prefer immediate rewards over equally high rewards in the future (also called "present bias"), the question arises as to how high the interest gain must be in order for people to abstain from immediate consumption in order to be able to collect a higher profit in the future (Frederick et al., 2002).

In the latter example, the time ratios are freely selectable and therefore clearly defined: An investor decides when to buy a security and what price to pay. The term, interest, and due date are fixed in advance. In such cases, the intertemporal nature of the decision is an objective reality. It gives the calculation of trade-offs a solid basis. This is not the case in many other decision-making situations. Even for investments in education, when or the extent to which they will pay off is unclear. In such cases, decision-makers must rely on assumptions, beliefs, and perceptions. In the case of decisions about the usage of digital technologies, it is often not obvious whether these are intertemporal choices at all, simply because it is unclear whether, when, or which violations of privacy or other types of costs may result from them. Often, it is just as unclear whether the anticipated benefit is concurrent with the use of the technology or emerges at a later point in time. Despite this uncertainty, we argue that most users treat decisions about the use of digital applications as intertemporal choices, doing so in such a way that they mentally shift the potential harm connected to taking a risk (i.e., potential violations of their informational privacy) into the distant future while remaining convinced they will enjoy the gains immediately. Of course, this does not rule out but rather includes situations in which there might be no risk assessment at all, because some users may be unaware of any risks concerning their behavior to begin with.

The tendencies to give different considerations to gains and losses based on their temporal manifestation might be explained by an optimistic bias in building specific expectancies concerning future events involving the self. That people's expectations about their personal futures are positive and often unrealistic is a robust and reliable finding in the study of the psychology of prediction and behavioral economics (Sharot, 2011; Weinstein \& Klein, 1996). When we make plans for the future, we are often overly optimistic. People tend not only to focus on the factors that improve their own chances of success, but also to neglect that others have the same factors in their favor (Weinstein, 2000). This comparative optimism has also been documented in online privacy research, which has shown that people assume others are more likely to be affected by data breaches and personal-information misuse than they are (Baek et al., 2014; Metzger \& Suh, 2017). A number of additional factors can explain unrealistic optimism, including self-serving biases, perceived control, being in a good mood, etc. (Armor \& Taylor, 1998; Shepperd et al., 2002). Optimism bias is assumed to be an evolutionary mechanism of maintaining mental health and coping in the face of arduous life conditions that permeate people's everyday decision-making (Sharot, 2011).

In our case, we conclude that optimism in technology-related expectancies leads users to assume that they will never or only in the unforeseeable future be affected by negative outcomes regarding their informational privacy. This may be true in some cases, but it is by no means mandatory or self-evident. For example, if credit card information is phished during an online shopping experience, it is highly likely that this information will be misused very soon. The same can happen with data revealing one's own consumption patterns or current state of health. Nevertheless, we assume that users will perceive the benefits they expect from the use of digital technology as accruing in the immediate present. In some situations, this will actually be the case. For instance, if one needs the timetable information for a train and consults an app on a smartphone, the information and thus the benefits will be available in real time. But even if the immediacy of the profit is not highly obvious, based on optimism, users will tend to perceive the anticipated utility as immediately realizable. Thus, users will always find a way to convince 
themselves of the immediacy of the profit they owe to digital applications, independent of the area of use. Importantly, we do not rule out the possibility that, sometimes, decisions about the use of digital technology are in fact intertemporal choices. We simply assume that they will regularly be treated as such, even if there is no reasonable justification for this assumption. In other words, we are dealing with a typical case of perceptual bias rather than rational consideration. Accordingly, our first hypothesis regarding people's perception of the time of occurrence of the beneficial or detrimental consequences of their actions is as follows:

H1: The expected time of occurrence of benefits is closer to the present than the expected time of occurrence of the expected losses.

\section{Time Discounting in the Application of the Online Privacy Calculus}

The most frequently used concept in the analysis of intertemporal choice is time discounting, that is, the tendency of people to downgrade (discount) the subjectively perceived value of events that lie in the future. This means that positive events in the future are less appreciated than similar ones in the present, and the further in the future negative events lie, the more the discomfort of negative events decreases. The greater the time interval, the greater the discount and the stronger its effect on the impending decision (Chapman, 1998; Frederick et al., 2002). The economics literature has typically been concerned with discounted utility, a term used to indicate that most economic entities would rather have gratification, a payout, or a positive experience today than in the future. This phenomenon is known as "present bias" (O'Donoghue \& Rabin, 1999). Once rewards are very distant in time, they cease to be valuable (Laibson, 1997). Present bias also means that people prefer a short-term profit to a higher profit they have to wait for. The degree of depreciation is expressed in a so-called discount rate. The original discounted utility model (Samuelson, 1937) led to numerous modifications of the original discount function (Chabris et al., 2010). For our study, more important than the calculation of discount rates is not only whether the prospect of profit loses its attraction the further the profit is postponed into the future but also whether the significance of possible losses (i.e., privacy risks) decreases when they lie in the future. In an empirical study, Thaler (1981) showed that the further something was into the future, the lower the weight people attached to a payment they had to make. However, the discount rate for losses is lower than that for profits. This observation is called the sign effect (Loewenstein \& Thaler, 1989, p. 187). There have been similar findings in the literature on risk perception. Various studies have shown that the greater the time lag between risky behavior and the assumed outcome, the lower the estimation of the average severity of a risk (Hendrickx et al., 1992; Nicolaij \& Hendrickx, 2003; Svenson \& Karlsson, 1989). Apparently, there is between-subject variance in discounting behavior as well as differences between use cases. Hendrickx and Nicolaij (2004) found that on the basis of ethical considerations, a large proportion of respondents do not discount future environmental damage. Moreover, although discount rates are positive for environmental risks, they are lower than for financial and health risks (Hendrickx \& Nicolaij, 2004).

Regarding the psychological mechanisms underlying intertemporal choices, time discounting has been ascribed to a combination of mortality, salience, and impatience effects (O'Donoghue \& Rabin, 1999). Other authors have extended the range of explanations. Based on the inconsistency between the patient, long-run self and the myopic, short-run self, dual-self models are used in economics to explain phenomena such as future discounting (Fudenberg \& Levine, 2006). It is assumed that humans distinguish between their present and later selves and that the well-being of the later self, which-so to speak-is a different person, is less important than that of today's self and is therefore traded for the benefit of today's self. In everyday life, people feel rather disconnected from their future selves, often ignoring that they are the future victims of their present (risky) behavior, as demonstrated by widespread harmful behavior, such as substance abuse and overeating (Abarca-Gómez et al., 2017; Whiteford et al., 2013). Consequently, as growing research has suggested, their behavior is assumed to be largely influenced by the short-term self and its respective short-term preferences (Amlung et al., 2016; MacKillop et al., 2011). Based on the aforementioned literature on intertemporal choices, we assume that there is a direct connection between the expected time of occurrence of a benefit or loss and its expected overall extent. More specifically, it is expected that the further away in the future the risk of danger seems, the less frightening it appears to be. With regard to the short-term self, we assume that the closer an anticipated profit is temporally, the more tempting and powerful it appears. To test the argument developed thus far, we derive two further hypotheses.

H2: The earlier the expected time of occurrence of the benefit, the higher the perceived amount of the benefit. 
H3: The later the expected time of occurrence of the loss, the lower the perceived amount of the loss.

The aforementioned mechanisms, then, are also of importance when it comes to temporal considerations regarding the online privacy calculus. Decisions about data disclosure not only bring about immediate consequences, but potentially exert their influence well into the future. That is, because personal data are saved and stored on a long-term basis, effects may be experienced at any point in time after the act of disclosure. Under conditions of incomplete information concerning future beneficial or unfavorable consequences and over long periods of time, it is thus not only complicated to make valid assumptions, but such assumptions will be influenced by the distorting mechanisms mentioned above, leading to a bias. With regard to the result of the privacy calculus, this leads to a fairly straightforward assumption. The perceived time interval between the immediate profit and the deferred threat of damage will generally lead to a balance that shows a surplus of benefits.

H4a: The perceived benefits exceed the perceived losses.

Finally, following the original privacy calculus model, our final hypothesis is as follows:

H4b: The perceived benefit of a given digital technology will be positively correlated with its usage, whereas the perceived loss of privacy will be negatively correlated with its usage. The positive effect of the benefits will be stronger than the negative effect of the loss.

One might also assume that there are direct effects of the presumed delay/immediacy of technology-use consequences, that is, the consequences' temporal quality that are not mediated by the expected amount of the benefit and damage. In addition to the present bias, it may be that benefits or losses that lie at some point in the future do not influence overall estimations of benefit or loss perceptions in the immediate present, but have a direct explanatory value for usage behavior that goes beyond the extent of potential consequences. Such additional mechanisms in time discounting have also been addressed in the literature (Berns et al., 2007). For instance, the anticipation of an event may come with a distinct affective quality, such as when one looks forward to a reward or dreads a loss (Loewenstein, 2006). As such, mental representations of consequences and their imagined temporal nature, especially concerning their certainty, may not be wholly reflected in the expected benefits or losses but may still affect behavior (Kahnemann et al., 1982). That means that usage may be influenced not only by the overall amount of benefits or losses but also by their expected time of occurrence. Because the quality and consequences of the mental event in which people imagine future repercussions may be manifold, we formulate an additional research question concerning the effect of the expected time of occurrence of benefits and losses on behavior:

RQ1: To what extent do expectations concerning the time of occurrence of benefits and losses that are not mediated by perceptions of the amount of benefits and losses explain usage behavior?

In terms of the online privacy paradox, a considerable amount of research has focused on social media and the use of SNSs, where extensive self-disclosure about private matters apparently conflicts with most notions of careful privacy management. However, the conflict between data disclosure and privacy intrusions cannot be neglected in several other online spheres with heavy user engagement and heightened societal relevance. After all, it has been widely documented that privacy concerns must be addressed situationally, because decisions about personal-information disclosure vary considerably by context (Bol et al., 2018; Petronio, 2002; Teutsch et al., 2018; Westin, 1967). Moreover, not only is the disclosure of information heavily context dependent, but in the evaluation of different goods (e.g., money, health), varying time intervals also cause distinct difficulties (Loewenstein \& Thaler, 1989). Consequently, in an attempt to understand the privacy paradox, we aim to broaden the perspective beyond self-disclosure on SNSs. First, economic research has focused on e-commerce as an avenue for online privacy research, investigating the price tag that users put on their private data (Acquisti, 2004; Hann et al., 2007; Metzger, 2004). When it comes to e-commerce, an economic cost-benefit analysis, such as the privacy calculus, relies on a currency that is easily assessable, that is, money, hence serving as a prime example of privacy-related decisionmaking, because more than 47 million Germans are considered e-commerce users (Statistisches Bundesamt, 2016). Second, since the advent of widespread public internet use, there has been great anticipation of a revitalization of the democratic process in liberal democracies. However, users who engage in online political participation leave information traces that can potentially be used to identify them and draw conclusions about 
their political stances and personal characteristics (Jernigan \& Mistree, 2009; Sweeney, 2000). Although the resulting dangers hinge on the political conditions in a given country and are thus difficult to calculate in advance, we emphasize the importance of investigating the cost-benefit analysis of online users regarding online political participation. Third, although the phenomenon of documenting one's daily activities, that is, self-tracking, is well established, the scope of such digital data collection has increased in recent years (Neff \& Nafus, 2016). New digital technologies such as wearables, that is, computer devices worn on the body, and the permanent online connectivity provided by the use of smartphones allow users to continually collect personal data regarding their physical and mental conditions. It is hardly surprising that the collection of such intimate information has raised serious privacy concerns (Aktypi et al., 2017). It is thus of interest whether the novelty of potentially widespread digital self-tracking, which allows for the gathering of highly sensitive personal data, affects the cost-benefit analysis, especially in the face of the assumed time discounting.

We introduced the aforementioned contexts to allow for a closer look at the potential similarities and differences of the human decision-making process in the context of the disclosure of personal information on the internet. Each of the three contexts addresses a rather narrow but decisive type of disclosed personal data that allows for highly intimate inferences about an individual's consumption preferences, political leaning, and health; collectively, however, the contexts cover a comprehensive set of privacy-relevant online behaviors. Consequently, we sought to answer the following research question:

RQ2: To what extent do prerequisites and the application of the privacy calculus vary between distinct fields of online activity, that is, e-commerce, online political participation, and self-tracking?

\section{Method}

To test the hypotheses, a split questionnaire-based online survey with three groups representing the different fields of activity-e-commerce, online political participation, and self-tracking-was conducted. All the respondents were randomly assigned to one of the three aforementioned groups. The field of activity of each group was briefly explained in the preface of the measurement to ensure a basic understanding of the respective context (see List 1 in Appendix B). In the absence of explicit mentions, there were no differences between the respective groups regarding the other measures described below. The study setting was in Germany. Data were obtained between the 5th and 13th of December 2017 via the online-access panel of the market research institute respondi, which is certified in accordance with the ISO 26362 norm.

\section{Sample}

The sample consisted of a quota sample of the population of internet users living in Germany, who were of a minimum age of 14 years. ${ }^{1}$ An internet user was defined as a person who uses the internet for private purposes at least once weekly. The respondents were invited to participate by respondi and received monetary compensation as an incentive.

Altogether, 1,320 participants completed the questionnaire. Due to quality fail criteria, such as time checks, the datasets of 206 participants were eliminated, resulting in a final sample of $N=1114$; thus, the sample sizes of the e-commerce $(n=372)$, online political participation $(n=375)$, and self-tracking $(n=367)$ split groups were equal. Among the whole sample, there were 565 (50.7\%) men and 549 (49.3\%) women, representing a balanced gender distribution. The average participant's age was 45 years $(S D=15.54)$, with the youngest participants being 14 and the oldest participants being 70 years old. Regarding educational level, 332 respondents (29.8\%) had a low, 375 (33.7\%) had a middle, and 407 (36.5\%) had a high level of educational attainment. ${ }^{2}$ These values match the quota criteria for Germany by AGOF (2017), as of October 1, 2017. Notably, the quota criteria also held true for the split groups.

\section{Measurements}

Because data were obtained in reference to the specific field, the questions and response options differed among the split groups for each respective data context. In what follows, the measurements of these particular variables are explained. All items and their wording can be found in List 1 in Appendix B. 


\section{Perceptions of Benefits and Losses}

Perceptions of benefits and losses were measured via four items each that we formulated and that lay on a 7point Likert scale $(1=$ do not agree at all to $7=$ do strongly agree $)$. In the e-commerce context, the participants were asked to rate statements with the introductory text "The fact that I can shop online ..."; in the online political participation context, they were asked to do so with the introductory text "The fact that I can inform myself about politics and can participate in a political context ..."; and in the self-tracking context with the introductory text "The fact that I can use digital technology to track data about my physical activities and my health..." For each context, four items addressed benefits and four addressed losses. An example of a gain item was "[Data context] is of benefit for me." An example of a risk item was "[Data context] is of disadvantage for me." The presentation order of all the items was randomly rotated. Cronbach's a and the average variance extracted showed good reliability values for each scale (see Table 3 in Appendix B), and for further analysis, the mean indices for the perceptions of benefits and losses were calculated for each data context.

\section{Perceived Occurrence of Benefits and Losses}

To evaluate the estimated time of occurrence of the benefits and losses, respectively, the participants were asked when-if at all-the risks or gains in a given field of activity would occur. The two items were measured on a 7point scale ( $1=$ today to $7=$ in the far away future). Alternatively, the participants could indicate that they perceived "no benefit or loss at any point in the future." Strictly speaking, this answer cannot be appropriately mapped onto a quasi-metric measure. However, the perception that an event will never occur also carries important information for the calculus. Thus, for the purpose of analysis, we assigned this answer the value of 8 , placing it one unit further away than "in the far away future."

\section{Usage of Digital Applications Regarding E-commerce, Online Political Participation, and Self-Tracking}

The usage behavior of the actual applications of a subsample was used as a dependent behavioral variable in the subsequent analyses. When it came to privacy-related disclosure of personal data and usage behavior, we decided to measure the general propensity to use digital applications that come with certain privacy risks and not only the intensity of their usage. Because each user may also have distinct interests and expectations concerning digital applications from a specific context, such as multifaceted online political participation or self-tracking, the proposed measure was broad enough to capture this openness to using data-collecting technology. Below, we document the indicators, measurements, and eventual distribution of each behavioral variable.

\section{E-Commerce}

In the e-commerce group, the participants were asked to estimate how much of their private shopping activity they conducted online (ranging from $0 \%$ to $100 \%) .{ }^{4}$ On average, they reported making 40 percent $(S D=26.56)$ of their purchases online. The surprisingly high number of reported online purchases might be explained by the exclusive presence of online users in the sample and the general difficulty for users to accurately recall the extent of their online shopping activities. However, although the overall amount might be overly high, we assume that overestimation bias affects all users equally, thus allowing for differentiation between low and high engagement.

\section{Online Political Participation}

To estimate the use of political applications, the participants were presented with 11 distinct opportunities for online political participation. They were asked to indicate whether they performed specific activities in the last 12 months (e.g., "I participated in political online discussions" or "I signed a petition"). In some parts, the items were adapted from prior research (Gil de Zúñiga et al., 2012; Kruikemeier et al., 2014). However, to better reflect the broadness of online political participation, we extended these scales with additional items (see Appendix B). All the positive answers were then summed for a final usage score ranging between 0 and $11(M=2.97, S D=2.90)$. 


\section{Self-Tracking}

As in the use of political applications, self-tracking usage in the preceding 12 months was measured with 12 items. For instance, the respondents were asked about using digital applications for self-tracking (e.g., "I tracked my daily steps" or "I documented my health condition"). Again, all positively answered items were summed so that the usage score for self-tracking that reflects the broadness of behavior ranged between 0 and $12(M=2.09, S D=2.87)$.

\section{Results}

To evaluate $\mathrm{H} 1$, we conducted paired $t$-tests that compared the expected time of occurrence of benefits with the expected time of occurrence of losses for the three respective fields of activity. Based on the results reported in Table 1, potential gains and losses were expected, on average, to occur at different points in time. The difference was significant for e-commerce $(t(362)=9.00, p<.001)$ and online political participation $(t(359)=3.26, p<.01)$ but not for self-tracking $(t(359)=1.495, p=.136$.). More specifically, the use of e-commerce shows the biggest temporal difference, with a one-scale-point difference between expected benefits and expected losses. For online political participation, this temporal difference amounted to half a scale point; for self-tracking, it amounted to a difference of only about a fifth of a scale point. For e-commerce, $24.8 \%$ of the respondents expected the benefits and losses to occur simultaneously; for online political participation, 36.4\% of the respondents had this expectation; and for self-tracking, 33.9\% had this expectation.

Table 1. Means and Standard Deviations for the Constructs Used in Each Field of Activity.

\section{Field of Activity}

E-commerce

\section{Variable}

Perception of losses

Perceived occurrence of losses

Perception of benefits

Perceived occurrence of benefits

Relative number of purchases made online

\section{M}

$S D$

$2.54 \quad 1.26$

$4.76 \quad 1.83$

$5.39 \quad 1.26$

$3.51 \quad 1.89$

40.01

26.56

Political online participation

$\begin{array}{lll}\text { Perception of losses } & 2.52 & 1.37 \\ \text { Perceived occurrence of losses } & 4.96 & 1.99 \\ \text { Perception of benefits } & 4.19 & 1.80 \\ \text { Perceived occurrence of benefits } & 4.52 & 2.21 \\ & & \\ \text { Usage score of participation activities } & 2.97 & 2.90\end{array}$

Self-tracking

$\begin{array}{lll}\text { Perception of losses } & 2.98 & 1.60 \\ \text { Perceived occurrence of losses } & 4.76 & 1.93 \\ \text { Perception of benefits } & 4.08 & 1.72 \\ \text { Perceived occurrence of benefits } & 4.59 & 2.05 \\ & & \\ \text { Usage score of self-tracking activities } & 2.09 & 2.87\end{array}$


Figure 1. Path Model With All Tested Effects of Loss and Benefit Perceptions on Usage Behavior.

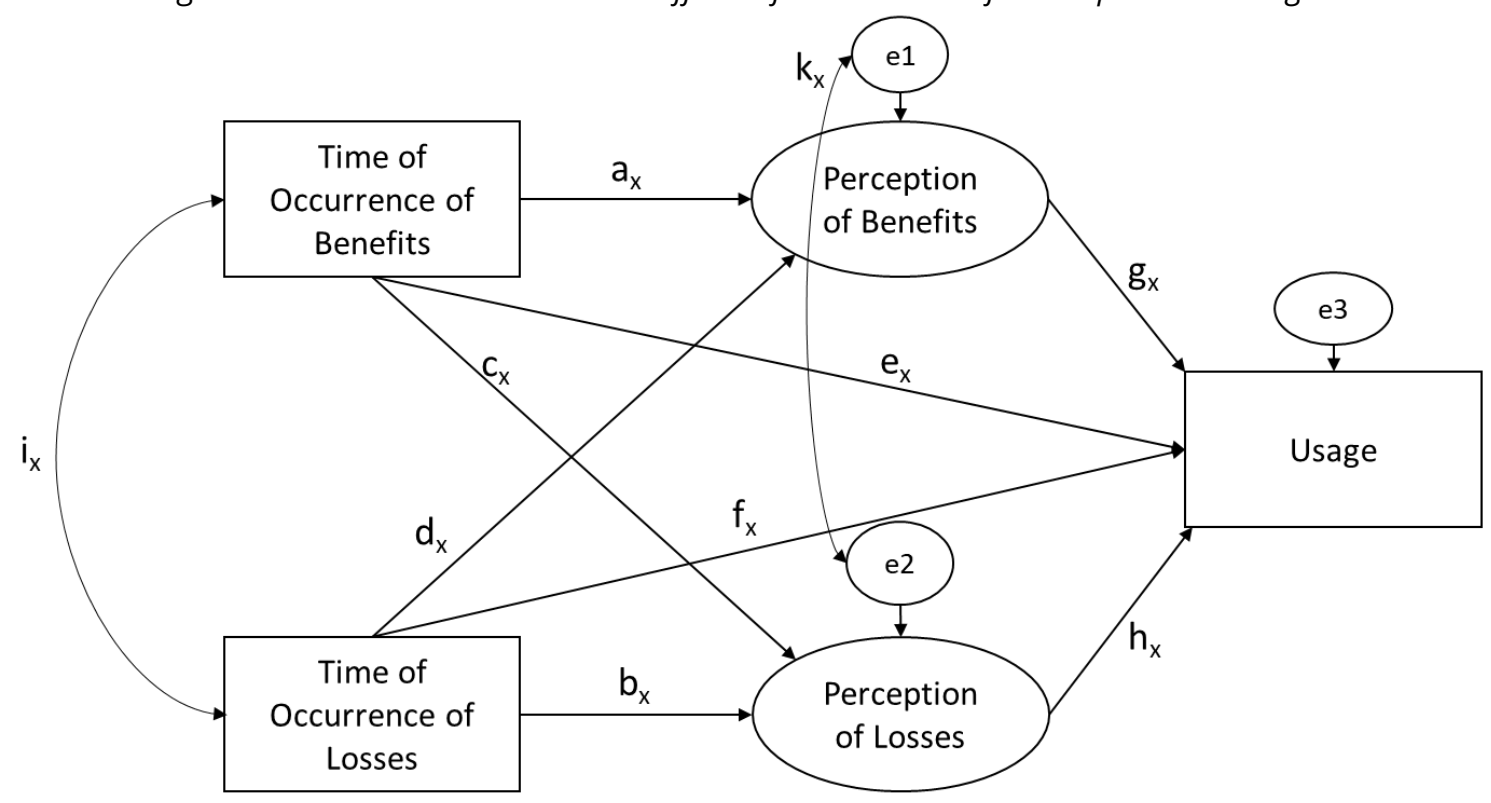

Although there were minor differences regarding the expected time of occurrence of benefits and losses, depending on the respective context, $\mathrm{H} 1$ was partially accepted. Between $65 \%$ and $75 \%$ of all respondents actually perceived technology-related decisions as intertemporal choices.

Table 2. Path Model for All Tested Effects (H2-H4).

\begin{tabular}{|c|c|c|c|c|c|c|c|c|c|c|c|c|}
\hline \multirow[t]{2}{*}{ Path } & \multicolumn{4}{|c|}{$\begin{array}{c}\text { E-Commerce } \\
(x=1)\end{array}$} & \multicolumn{4}{|c|}{$\begin{array}{l}\text { Political Online Participation } \\
\qquad(x=2)\end{array}$} & \multicolumn{4}{|c|}{$\begin{array}{c}\begin{array}{c}\text { Self-Tracking } \\
(x=3)\end{array} \\
\end{array}$} \\
\hline & $B$ & $S E$ & $C R$ & $\beta$ & $B$ & $S E$ & $C R$ & $\beta$ & B & $S E$ & $C R$ & $\beta$ \\
\hline $\begin{array}{l}\text { a: Time of Occurrence of Benefits -> } \\
\text { Perception of Benefits }(\mathrm{H} 2)\end{array}$ & $-0.228^{\star \star \star}$ & 0.034 & -6.687 & -.346 & $-0.334^{\star \star \star}$ & 0.043 & -7.862 & -.405 & $-0.390^{\star \star \star}$ & * 0.041 & -9.402 & -.460 \\
\hline $\begin{array}{l}b_{x}: \text { Time of Occurrence of Losses -> } \\
\text { Perception of Losses }(\mathrm{H} 3)\end{array}$ & $-0.143^{\star \star \star}$ & 0.034 & -4.202 & -.228 & $-0.162^{* \star *}$ & 0.040 & -4.014 & -.223 & $-0.223^{* * *}$ & * 0.040 & -5.605 & -.294 \\
\hline $\begin{array}{l}\text { C }_{x} \text { : Time of Occurrence of Benefits -> } \\
\text { Perception of Losses }\end{array}$ & $0.115^{\star \star *}$ & 0.033 & 3.474 & .189 & $0.082^{*}$ & 0.036 & 2.259 & .126 & $0.208^{* \star *}$ & 0.038 & 5.439 & .290 \\
\hline $\begin{array}{l}d_{x}: \text { Time of Occurrence of Losses -> } \\
\text { Perception of Benefits }\end{array}$ & 0.036 & 0.035 & 1.018 & .052 & 0.054 & 0.048 & 1.141 & .059 & $0.186^{* * *}$ & 0.043 & 4.287 & .207 \\
\hline$e_{x}:$ Time of Occurrence of Benefits -> Usage & -0.409 & 0.728 & -0.562 & -.029 & $-0.178^{* *}$ & 0.068 & -2.609 & -.136 & $-0.211^{\star *}$ & 0.078 & -2.715 & -.151 \\
\hline$f_{x}$ : Time of Occurrence of Losses -> Usage & $1.700^{*}$ & 0.728 & 2.334 & .117 & -0.081 & 0.072 & -1.127 & -.055 & -0.049 & 0.076 & -.642 & -.033 \\
\hline$g_{x}:$ Perception of Benefits -> Usage (H4b) & $8.455^{\star \star \star}$ & 1.304 & 6.482 & .396 & $0.634^{* \star *}$ & 0.083 & 7.677 & .400 & $0.521^{\star \star *}$ & 0.097 & 5.390 & .316 \\
\hline$h_{x}$ : Perception of Losses -> Usage & 1.739 & 1.404 & 1.238 & .075 & 0.001 & 0.100 & 0.010 & .001 & -0.063 & 0.111 & -.569 & -.032 \\
\hline $\mathrm{i}_{\mathrm{x}}$ & -0.137 & 0.182 & 0.757 & -.040 & $1.170^{\star \star \star}$ & 0.240 & 4.884 & .267 & $0.681^{* *}$ & 0.212 & 3.212 & .173 \\
\hline $\mathrm{k}_{\mathrm{x}}$ & $-0.520^{\star * *}$ & 0.085 & -6.124 & -.408 & $-0.369^{* *}$ & -0.133 & -2.769 & -.157 & $-0.608^{* * *}$ & * 0.124 & -4.899 & -.293 \\
\hline \multicolumn{13}{|l|}{ Model Fit - Constrained Model } \\
\hline$\chi^{2}(d f)$ & \multicolumn{4}{|c|}{$149.466(41)$} & \multicolumn{4}{|c|}{$77.359(40)$} & \multicolumn{4}{|c|}{95.424 (39) } \\
\hline$p$ & \multicolumn{4}{|c|}{$<.001$} & \multicolumn{4}{|c|}{.001} & \multicolumn{4}{|c|}{$<.001$} \\
\hline $\mathrm{CFI}$ & \multicolumn{4}{|c|}{.946} & \multicolumn{4}{|c|}{.989} & \multicolumn{4}{|c|}{.981} \\
\hline TLI & \multicolumn{4}{|c|}{.913} & \multicolumn{4}{|c|}{.982} & \multicolumn{4}{|c|}{.969} \\
\hline RMSEA & \multicolumn{4}{|c|}{$.084(.070, .099)$} & \multicolumn{4}{|c|}{$.045(.027, .0 .62)$} & \multicolumn{4}{|c|}{$.063(.047, .079)$} \\
\hline
\end{tabular}

Note. ${ }^{*} p<.05,{ }^{* *} p<.01,{ }^{* \star *} p<.001$.

To test the remaining hypotheses and address the research questions, we subsequently conducted a path analysis based on covariance-based structural equation modelling using the statistical software package IBM SPSS AMOS 27. We tested the paths in the mediation model in Figure 1 using full information maximum likelihood estimation. The means and intercepts were estimated to account for missing values. To test all our assumptions, all possible effects were introduced into the default model, which was fully specified. Accordingly, there were no model fit 
statistics for the default model. After testing the effects, we respecified the default model, constrained all the nonsignificant paths to zero, and reported the fit statistics for the final model (see Table 2; respecified models are presented in Figures 2-4, Appendix A). To address the different variables used in the distinct data contexts described above, a unique model was estimated for each field of activity. ${ }^{5}$ Consequently, each path in Figure 1 was identified by a letter, with the subscript $x$ relating to the field. The estimates for all the effects can be found in Table 2.

$\mathrm{H} 2$ postulated a relation between the expected time of occurrence of benefits and the perceived amount of these benefits, namely reward discounting. It was, therefore, included as path $a_{x}$ in Figure 1 , and the results can be found in the first row of Table 2 . For the path $a_{x}$, there was a moderate effect in the fields of e-commerce $\left(\beta_{a 1}=-.346\right)$, online political participation ( $\left.\beta_{\mathrm{a} 2}=-.405\right)$, and self-tracking $\left(\beta_{\mathrm{a} 3}=-.460\right)$. All effects were statistically significant, which means that the closer in time the expected benefits were from using applications in the context of e-commerce, online political participation, and self-tracking, the higher was the overall amount of the perceived benefits of using such applications, thereby reflecting present bias with different discount rates in the respective use cases. Accordingly, $\mathrm{H} 2$ was accepted.

Similarly, $\mathrm{H} 3$ inquired about the relation between the expected time of occurrence of damage and the perceived amount of damage, namely risk discounting. It was expected that the more distantly in the future losses were expected to occur, the smaller the perceived losses. For e-commerce $\left(\beta_{b 1}=-.228\right)$, online political participation $\left(\beta_{\mathrm{b} 2}=-.223\right)$, and self-tracking $\left(\beta_{\mathrm{b} 3}=-.294\right)$, the expected relation showed that the later the losses were expected, the lower was the overall perceived amount of losses. The respondents tended to discount the severity of a privacy-related risk when they perceived a temporal delay of its negative consequences. Thus, H3 was accepted.

In addition to the direct effects tested in $\mathrm{H} 2$ and $\mathrm{H} 3$, the results showed that there were crossover effects of time discounting, such that an immediate benefit further reduced the risk assessment (direct effect $c_{x}$ in the third row of Table 2). This was indicated by a direct effect for e-commerce $\left(\beta_{c 1}=.189\right)$, online political participation $\left(\beta_{\mathrm{c} 2}=\right.$ $.126)$, and self-tracking $\left(\beta_{\mathrm{c} 3}=.290\right)$. The sooner the expected benefits materialized, the smaller the perceived losses. Moreover, expectations of more distant damage increased the perceived benefit, but only in the case of self-tracking applications ( $\beta_{\mathrm{d} 3}=.207$; direct effect $d_{x}$ in the fourth row of Table 2 ).

The previous tests laid the foundation for the eventual calculus. H4a stated that the perceived benefits were more pronounced than the perceived losses. As Table 1 shows, the perceived benefits exceeded the losses in each context by at least one scale point (and as many as 2.8 scale points in the case of e-commerce). The paired $t$-tests indicated that the difference was significant for e-commerce $(t(371)=25.78, p<.001)$, online political participation $(t(374)=13.26, p<.001)$, and self-tracking $(t(366)=7.63, p<.001)$. Furthermore, as indicated by the negative correlation between the error terms of the benefit and loss perceptions ( $k_{x}$ in Figure 1$)$, the higher the benefits, the lower the perceived losses. Thus, H4a was accepted.

Furthermore, $\mathrm{H} 4 \mathrm{~b}$ addressed the assumed effects of loss and gain perceptions on usage behavior. Referring to the path model, the predictive value of the benefit perception on usage behavior was tested (direct effect $g_{x}$ in Table 2). The results indicated that there was a significant direct effect of benefit perceptions on usage behavior for e-commerce $\left(\beta_{\mathrm{g} 1}=.396\right)$, online political participation $\left(\beta_{\mathrm{g} 2}=.400\right)$, and self-tracking $\left(\beta_{\mathrm{g} 3}=.316\right)$. In combination with the direct effect $\beta_{\mathrm{ax}}$, this suggests indirect effects (the product of the direct effects $a_{\mathrm{x}}$ and $g_{\mathrm{x}}$, i.e., $\beta_{\text {ind } 1}=-.14$, $\beta_{\text {ind2 }}=-.16$ and, respectively, $\beta_{\text {ind } 3}=-.15$ ) of the perceived occurrence of benefits on usage behavior. However, the data showed no significant effects of loss perceptions on usage behavior, irrespective of the context of inquiry (direct effect $h_{x}$ in Table 2). As there was no such effect in the first place, the comparisons of the effect size were negligible. Accordingly, whereas we found the postulated positive effect of the benefit perceptions, the same could not be said about the presumed influence of the loss perceptions. Consequently, H4b was partially accepted.

Finally, $\mathrm{RQ}_{1}$ asked whether there were direct effects (direct effects $e_{x}$ and $f_{x}$ in Table 2 ) of the expected time of occurrence of benefits and losses on usage behavior that could not be explained by indirect effects via the privacy calculus, that is, the mediation of the effects by the perception of the amount of benefits and losses. Regarding ecommerce, the results indicated a small positive direct effect of the expected time of occurrence of losses (direct effect $f_{1}, \beta_{f 1}=.117$ ) on the relative number of online purchases. The later expected losses manifested themselves, the more the respondents engaged in e-commerce. Conversely, for online political participation $\left(\beta_{\mathrm{e} 2}=-.136\right)$ and 
self-tracking ( $\left.\beta_{\mathrm{e} 3}=-.151\right)$, there were small negative direct effects of the expected time of occurrence of benefits. This means that the sooner the benefits were expected, the higher was the usage of online tools in the respective field of activity. Consequently, there was partial mediation of the expected time of occurrence of benefits by the amount of perceived benefits in the case of online political participation and self-tracking and full mediation in the case of e-commerce.

The explanations offered above indicate that the conditions for the online privacy calculus were not identical in all the examined fields of activity. Thus, the answer to RQ 2 is "Yes, context matters."

\section{Discussion}

This paper set out to extend research on the so-called privacy calculus model by taking into account perceptions of expected benefits and losses and by introducing the temporal perceptions of their respective time of occurrence. It is argued that this so-called online privacy paradox can be explained by a rational cost-benefit analysis (Culnan \& Armstrong, 1999; Laufer \& Wolfe, 1977). As soon as the benefits of using an application outweigh the expected costs, the resulting balance should accurately predict the extent of usage of digital applications. However, as theories from behavioral economics argue, users might not be rational agents making economically sound decisions. Human decision-making is subject to certain misconceptions and biases that result from insufficient information, bounded rationality, and other deviations from rationality (Acquisti \& Grossklags, 2005; Loewenstein et al., 2003; Loewenstein \& Thaler, 1989). In this paper, we focused on temporal expectations of the occurrence of benefits and losses as an aspect of nonrational decision-making.

The reported results indicate that most users expect benefits and losses to occur at different points of time and that in aggregate, users ordinarily perceive the occurrence of benefits before any occurrence of loss or damage from engaging in online shopping and online political participation, but not for self-tracking (H1). This suggests that users tend to treat the potential consequences of using digital applications as intertemporal choicesdecisions whose consequences manifest at different time points in the future. This strengthens the argument that the calculus should be understood to include not only a rational weighing of the general pros and cons of data disclosure but also judgements that involve uncertainty and a susceptibility to error. Furthermore, the benefits derived from the usage of digital applications are expected to manifest earlier than the losses for the contexts of e-commerce and online political participation, suggesting an optimistic user bias. Here, self-tracking may deviate, because the nature of its goals, such as weight loss or health improvements, are incremental and can be realized only over longer periods. It may also be more doubtful whether one can realize them at all. Next, for $\mathrm{H} 2$, the data show that the sooner the respondents expected the benefits, the higher their overall perceived utility of using online shopping, online political participation, and self-tracking. Thus, not only did the users expect the benefits to materialize earlier than the losses; they also expected the earlier occurrence of benefits to increase the overall use that they expected in all the investigated fields of online activity. Consequently, the data suggest the existence of present bias, leading to reward discounting; that is, the amount of expected benefits was actually dependent on the expected time of their occurrence. For the expected time of occurrence of losses and the overall expected losses, the inverse relationship of risk discounting was not consistently present in all fields of online activity. This might be attributed to the joint consideration of perceived benefits and losses in the calculus, in which the expected immediacy of benefits outweighed the losses and their expected time of occurrence. It also calls for further assessment of the actual calculation of benefits and losses performed by users and the respective modelling of the calculation. The analysis at hand followed prior research in the parallel modelling of benefits and losses as distinct causes. Alternatives, including a weighted score of perceived value based on the levels and the ratio of expected benefits and losses, may be considered. At the same time, such alternatives need to be carefully theorized and judged by increasing explanatory power. Only for self-tracking did the expected time of occurrence of losses have an influence on the amount of losses. More specifically, the sooner the respondents expected the losses to materialize, the greater were the perceived losses. This could be explained by the fact that a crucial component of self-tracking applications is the time aspect itself, that is, becoming or staying healthy; thus, it might be easier for the respondents to identify the occurrence of benefits and losses. Moreover, because self-tracking is a rather recent phenomenon and respondents indicated rather low usage of self-tracking applications, we argue that this lack of experience might have led them to take a more careful approach, which may explain the contextual differences. It is also conceivable that the German respondents might have been warier of the misuse of personal information concerning a person's physical and mental conditions. 
To account for the widespread use of digital applications, the confirmation of H4a set the stage for the final inspection of the online privacy calculus. For a general public adoption and extensive use of networked digital systems, the expectations of personal benefits have to outweigh the concerns over such usage. This refers to the core rational choice logic of the online privacy calculus, which posits that users are, by and large, driven by the utility they derive from digital services. Delving deeper into the privacy calculus and turning to $\mathrm{H} 4 \mathrm{~b}$, the results demonstrate that the perceived benefits are actually the main driver of usage in all three fields of online activity. Conversely, perceptions of losses had no impact on usage for the respective activities. All in all, the perceived potential losses were not only generally lower than the perceived benefits, but they also failed to explain usage behavior to begin with. This finding contradicts previous evidence of a negative influence; thus, we calls for further consideration of the theoretical implications of the online privacy calculus model in questioning the interrelations of benefit and loss perceptions. Previous research has often modelled benefit perceptions alongside loss perceptions (Dienlin \& Metzger, 2016; Trepte et al., 2017) or assumed loss perceptions as a preceding influence on benefit perceptions in explaining usage (Taddicken, 2014). With reference to the reported findings on the relation of perceptions of benefits and losses-i.e., higher benefit perceptions go hand in hand with lower loss perceptions-this, too, supports the need for a closer look into the actual calculation process of users. Although our findings suggest that benefit perceptions alone are decisive in usage behavior, research that specifically addresses distinct proportions of loss and benefit perceptions might shed light on the intricacies of presumably rational decision-making. Due to restrictions in the sample size of this study, we could not pursue such considerations further. As such, it is striking that with regard to $\mathrm{RQ}_{1}$, there were direct effects of the expected time of occurrence of benefits and losses, although the differences between the investigated fields of online activity did not allow for a conclusive interpretation. For the e-commerce field, the respondents who expected losses to materialize sooner bought fewer goods online. Thus, the perceived amount of losses had no effect on the use of e-commerce but rather on when such losses were expected to occur. The respondents who felt that damage could soon be inflicted and may have been particularly fearful reduced their online spending accordingly. Conversely, for online political participation and self-tracking, there was a direct negative effect of the time of occurrence of benefits on the range of usage; that is, the later the benefits materialized, the less use of such applications the respondents made. The results suggest that the anticipation of consequences has a distinct quality beyond the expectations and weighting of the benefits and losses themselves. Explanations may be found in the nature of both fields of activity and especially their mental representation and affective consequences (Berns et al., 2007). Although self-tracking may be perceived as tedious, with benefits accruing only gradually, the respondents who did not believe in the near-term benefits of online political participation-irrespective of its perceived potential utility-abandoned such behavior altogether. However, providing additional insights into the specific causes of this relationship that explain similarities as well as differences, which may be found in the nature of the respective contexts and specific perceived consequences of users, requires further research.

\section{Implications}

This study has important implications for companies and regulators and their dealings with users who may not accurately assess future consequences of present behavior. Organizations collecting user data should recognize that technology adoption is not solely a rational process but is also dependent on the perceived time of occurrence of potential risks and benefits and that such perceptions decisively differ according to the nature of the distinct fields of activity. As a result, data-processing entities not only need to inform users about what user data are stored and processed, but should also clarify what medium- and long-term hazards may exist as a result of data disclosure. Hence, although it might be beneficial for organizations and companies to highlight the near-future benefits of their products, they are ethically responsible not only for treating users' data carefully but also for responsibly managing users' expectations regarding privacy and usage of digital media. As a consequence, organizations could develop or strengthen corporate ethical guidelines to better educate and protect their users. Likewise, regulators should thoroughly evaluate the potential temporal dimensions of privacy risks associated with the use of online applications. Because the perception of near-time benefits outweighs long-term risks, regulators could then take countermeasures, such as legally requiring organizations to inform users about potential long-term privacy risks. 


\section{Limitations}

In general, this study has limitations insofar as only a certain number of fields of online activities could be chosen and, as a consequence, the measurement of perceived benefits and losses as well as the behavior of data disclosure are arguably abstract and broad. However, comparing e-commerce with online political communication and self-tracking allows for interesting insights. Money serves as currency in e-commerce, and any calculus that comes with the disclosure of data while shopping can be evaluated from a monetary economic perspective, because personal information is traded for presumably cheaper products and services. This exchange of "currency" is different for online political participation and self-tracking, which involve a different type of calculus, as supported by our findings.

We measured usage behavior for self-tracking as well as political participation as an additive index of a broad variety of different activities. Thus, this measure served as an indicator of openness to a huge variety of online technology in the specific field, but not for the actual frequency of the behavior. Hence, incidental users might also have reached a high value for reported behavior. Additionally, we measured online shopping behavior in only one variable, because it is the main activity in the field of e-commerce.

Lastly, we decided to assign perceptions of "no benefit/loss at any point in the future" to the extreme point of the variable time of occurrence of losses/benefits, that is, one unit greater than "in the far away future." In doing so, we included the temporal meaning of this information and were able to model it in the statistical model. Generally, results appeared to be robust when compared to a solution that excluded the information but came with lower statistical power. This decision came with two limitations: (1) the measure deviates from the quasi-metric character of the scale, and (2) one could argue that such an answer may not even be located on the scale at all.

\section{Conclusion}

When it comes to decision-making in relation to the use of digital applications that allow for extensive data collection, it is important to consider the benefits and risks that users perceive as well as when these benefits and risks are expected to materialize. Weaving together the insights articulated above, it can be summarized that the more benefits users perceive, the more likely they are to make extensive use of digital applications, reflecting the traditional approach to the privacy paradox in modelling a rational choice logic based on the privacy calculus. However, the weighting process, inherent to the calculus, also needs to account for potential biases that take into consideration the temporal dimension of decision-making under risk and uncertain outcomes. As our data suggest, users' perceptions concerning the time of occurrence of beneficial and detrimental consequences when engaging with networked digital systems and services play a decisive role in the ostensibly well-calibrated calculation process, allowing for a more detailed explanation of why the privacy paradox might not seem so paradoxical to users.

In light of the extensive use of networked digital systems in the impending information society, the evidence presented in our study calls for a sober assessment of conflicting individual needs against the backdrop of the often risky nature of digitalization and its effects on informational privacy.

\section{Footnotes}

1. We opted for a provider of an online open-access panel that is a member of European Society for Opinion and Market Research (ESOMAR) and certified according to ISO 26362. The latter warrants that the panel provider is externally audited to perform certain obligations, such as fulfilling requirements in terms of panel recruitment, data security and privacy, provision of information, and incentivizing of panel members. We did not let children (according to ESOMAR, persons under 14 years of age) participate in our survey. However, some young people (14-17 years of age) were allowed to participate only after we ensured that our questionnaire did not violate ESOMARs Codes and Guidelines INTERVIEWING CHILDREN AND YOUNG PEOPLE. There was no deception in our research, and we did not use questions that could have been traumatizing or deemed overly intimate. Regarding the reported behavior, participants could choose not to reveal certain activities. 
2. The question regarding the respondents' education included the eight most common educational qualifications in Germany. Although we reported three educational levels for the respondents' sociodemographic distribution, the analysis was based on an eight-point education variable.

3. Apart from excluding such cases and their information altogether-a solution in which results stayed robust, even though some effects were nonsignificant due to lower statistical power-another option would be to include the information in a dummy variable. However, due to the low number of cases for some variables, this leads to estimation problems in the statistical model.

4. In the questionnaire, respondents also had to indicate how many customer-loyalty cards they possessed. Because the distribution of this measure was unsatisfactory and not empirically connected to the reported amount of online shopping, we excluded the variable from our analysis. However, in the questionnaire, the following assessment of benefits and losses also addressed such cards and consequently needs to be regarded as a limitation, even though compared to the two other contexts, there are no issues concerning its explanatory power.

5. Because younger people presumably tend to use self-tracking apps more often, we also checked for confounding effects of participants' age on the model paths. Although the use of self-tracking indeed correlated with age in that younger people used more self-tracking applications $(r=.222, p<.001)$, when introduced as a control variable, age did not affect the mechanisms in the subsequently reported models.

\section{Acknowledgement}

The authors thank Pascal J. Kieslich for his thoughtful feedback on the paper.

\section{References}

Abarca-Gómez, L., Abdeen, Z. A., Hamid, Z. A., Abu-Rmeileh, N. M., Acosta-Cazares, B., Acuin, C., Adams, R. J., Aekplakorn, W., Afsana, K., Aguilar-Salinas, C. A., Agyemang, C., Ahmadvand, A., Ahrens, W., Ajlouni, K., Akhtaeva, N., Al-Hazzaa, H. M., Al-Othman, A. R., Al-Raddadi, R., Al Buhairan, F., . . Ezzati, M. (2017). Worldwide trends in body-mass index, underweight, overweight, and obesity from 1975 to 2016: A pooled analysis of 2416 population-based measurement studies in 128.9 million children, adolescents, and adults. The Lancet, 390(10113), 2627-2642. https://doi.org/10.1016/S0140-6736(17)32129-3

Acquisti, A. (2004). Privacy in electronic commerce and the economics of immediate gratification. In EC '04: Proceedings of the 5th ACM conference on Electronic commerce (pp. 21-29). ACM.

https://doi.org/10.1145/988772.988777

Acquisti, A., Brandimarte, L., \& Loewenstein, G. (2015). Privacy and human behavior in the age of information. Science, 347(6221), 509-514. https://doi.org/10.1126/science.aaa1465

Acquisti, A., \& Grossklags, J. (2005). Privacy and rationality in individual decision making. IEEE Security \& Privacy, 3(1), 26-33. https://doi.org/10.1109/MSP.2005.22

AGOF. (2017). Digital facts für Oktober 2017 [Digital facts for October 2017]. https://www.agof.de/servicedownloads/downloadcenter/download-daily-digital-facts/

Ajzen, I. (1991). The theory of planned behavior. Organizational Behavior and Human Decision Processes, 50(2), 179-211. https://doi.org/10.1016/0749-5978(91)90020-T

Ajzen, I. (2002). Perceived behavioral control, self-efficacy, locus of control, and the theory of planned behavior. Journal of Applied Social Psychology, 32(4), 665-683. https://doi.org/10.1111/j.1559-1816.2002.tb00236.x 
Aktypi, A., Nurse, J. R. C., \& Goldsmith, M. (2017). Unwinding Ariadne's identity thread: Privacy risks with fitness trackers and online social networks. In MPS '17: Proceedings of the 2017 on Multimedia Privacy and Security (pp. 111). ACM. https://doi.org/10.1145/3137616.3137617

Amlung, M., Petker, T., Jackson, J., Balodis, I., \& Mackillop, J. (2016). Steep discounting of delayed monetary and food rewards in obesity: A meta-analysis. Psychological Medicine, 46(11), 2423-2434.

https://doi.org/10.1017/S0033291716000866

Armor, D. A., \& Taylor, S. E. (1998). Situated optimism: Specific outcome expectancies and self-regulation. In M. P. Zanna (Ed.), Advances in experimental social psychology, (Vol. 30, pp. 309-379). London: Academic Press.

https://doi.org/10.1016/S0065-2601(08)60386-X

Baek, Y. M., Kim, E., \& Bae, Y. (2014). My privacy is okay, but theirs is endangered: Why comparative optimism matters in online privacy concerns. Computers in Human Behavior, 31, 48-56.

https://doi.org/10.1016/j.chb.2013.10.010

Barth, S., \& De Jong, M. D. T. (2017). The privacy paradox - Investigating discrepancies between expressed privacy concerns and actual online behavior - A systematic literature review. Telematics and Informatics, 34(7), 1038-1058. https://doi.org/10.1016/j.tele.2017.04.013

Baruh, L., Secinti, E., \& Cemalcilar, Z. (2017). Online privacy concerns and privacy management: A meta-analytical review. Journal of Communication, 67(1), 26-53. https://doi.org/10.1111/jcom.12276

Berns, G. S., Laibson, D., \& Loewenstein, G. (2007). Intertemporal choice - toward an integrative framework. Trends in Cognitive Sciences, 11(11), 482-488. https://doi.org/10.1016/j.tics.2007.08.011

Bol, N., Dienlin, T., Kruikemeier, S., Sax, M., Boerman, S. C., Strycharz, J., Helberger, N., \& de Vreese, C. H. (2018). Understanding the effects of personalization as a privacy calculus: Analyzing self-disclosure across health, news, and commerce contexts. Journal of Computer-Mediated Communication, 23(6), 370-388.

https://doi.org/10.1093/jcmc/zmy020

Chabris, C. F., Laibson, D. I., \& Schuldt, J. P. (2010). Intertemporal choice. In S. N. Durlauf \& L. E. Blume (Eds.), Behavioural and experimental economics (pp. 168-177). Palgrave Macmillan.

https://doi.org/10.1057/9780230280786_22

Chapman, G. B. (1998). Sooner or later: The psychology of intertemporal choice. In D. L. Medin (Ed.), The psychology of learning and motivation: Advances in research and theory (Vol. 38, pp. 83-113). Academic Press.

Choi, H., Park, J., \& Jung, Y. (2018). The role of privacy fatigue in online privacy behavior. Computers in Human Behavior, 81, 42-51. https://doi.org/10.1016/j.chb.2017.12.001

Culnan, M. J., \& Armstrong, P. K. (1999). Information privacy concerns, procedural fairness, and impersonal trust: An empirical investigation. Organization Science, 10(1), 104-115. https://doi.org/10.1287/orsc.10.1.104

Dienlin, T., \& Metzger, M. J. (2016). An extended privacy calculus model for SNSs: Analyzing self-disclosure and self-withdrawal in a representative U.S. sample. Journal of Computer-Mediated Communication, 21(5), 368-383. https://doi.org/10.1111/jcc4.12163

Frederick, S., Loewenstein, G., \& O'Donoghue, T. (2002). Time discounting and time preference: A critical review. Journal of Economic Literature, 40(2), 351-401. https://doi.org/10.1257/jel.40.2.351

Fudenberg, D., \& Levine, D. K. (2006). A dual-self model of impulse control. American Economic Review, 96(5), 1449-1476. https://doi.org/10.1257/aer.96.5.1449 
Gerber, N., Gerber, P., \& Volkamer, M. (2018). Explaining the privacy paradox: A systematic review of literature investigating privacy attitude and behavior. Computers \& Security, 77, 226-261.

https://doi.org/10.1016/j.cose.2018.04.002

Gil de Zúñiga, H., Jung, N., \& Valenzuela, S. (2012). Social media use for news and individuals' social capital, civic engagement and political participation. Journal of Computer-Mediated Communication, 17(3), 319-336.

https://doi.org/10.1111/j.1083-6101.2012.01574.x

Hann, I.-H., Hui, K.-L., Lee, S.-Y. T., \& Png, I. P.L. (2007). Overcoming online information privacy concerns: An information-processing theory approach. Journal of Management Information Systems, 24(2), 13-42.

https://doi.org/10.2753/MIS0742-1222240202

Hargittai, E., \& Marwick, A. (2016). "What can I really do?": Explaining the privacy paradox with online apathy. International Journal of Communication, 10, 3737-3757. https://doi.org/10.5167/uzh-148157

Hendrickx, L., \& Nicolaij, S. (2004). Temporal discounting and environmental risks: The role of ethical and lossrelated concerns. Journal of Environmental Psychology, 24(4), 409-422. https://doi.org/10.1016/j.jenvp.2004.12.001

Hendrickx, L., Vlek, C., \& Caljé, H. (1992). Effects of frequency and scenario information on the evaluation of large-scale risks. Organizational Behavior and Human Decision Processes, 52(2), 256-275.

https://doi.org/10.1016/0749-5978(92)90038-9

Hoffmann, C. P., Lutz, C., \& Ranzini, G. (2016). Privacy cynicism: A new approach to the privacy paradox. Cyberpsychology: Journal of Psychosocial Research on Cyberspace, 10(4), Article 7. https://doi.org/10.5817/CP2016-47

Infratest dimap. (2018). ARD DeutschlandTREND - April 2018. https://www.infratestdimap.de/fileadmin/user_upload/dt1804_bericht.pdf

Jernigan, C., \& Mistree, B. F. T. (2009). Gaydar: Facebook friendships expose sexual orientation. First Monday, 14(10). https://firstmonday.org/ojs/index.php/fm/article/download/2611/2302

Kahneman, D., Slovic, P., \& Tversky, A. (1982). Judgement under uncertainty: Heuristics and biases. Cambridge University Press.

Kokolakis, S. (2017). Privacy attitudes and privacy behaviour: A review of current research on the privacy paradox phenomenon. Computers \& Security, 64, 122-134. https://doi.org/10.1016/j.cose.2015.07.002

Krasnova, H., Spiekermann, S., Koroleva, K., \& Hildebrand, T. (2010). Online social networks: Why we disclose. Journal of Information Technology, 25(2), 109-125. https://doi.org/10.1057/jit.2010.6

Kruikemeier, S., van Noort, G., Vliegenthart, R., \& de Vreese, C. H. (2014). Unraveling the effects of active and passive forms of political Internet use: Does it affect citizens' political involvement? New Media \& Society, 16(6), 903-920. https://doi.org/10.1177/1461444813495163

Laibson, D. (1997). Golden eggs and hyperbolic discounting. The Quarterly Journal of Economics, 112(2), 443-478. https://doi.org/10.1162/003355397555253

Laufer, R. S., \& Wolfe, M. (1977). Privacy as a concept and a social issue: A multidimensional developmental theory. Journal of Social Issues, 33(3), 22-42. https://doi.org/10.1111/j.1540-4560.1977.tb01880.x

Loewenstein, G. (2006). The pleasures and pains of information. Science, 312(5774), 704-706.

https://doi.org/10.1126/science.1128388 
Loewenstein, G. F., Read, D., \& Baumeister, R. F. (Eds.). (2003). Time and decision: Economic and psychological perspectives on intertemporal choice. Russel Sage Foundation.

http://www.jstor.org/stable/10.7758/9781610443661

Loewenstein, G., \& Thaler, R. H. (1989). Anomalies: Intertemporal choice. Journal of Economic Perspectives, 3(4), 181-193. https://doi.org/10.1257/jep.3.4.181

MacKillop, J., Amlung, M. T., Few, L. R., Ray, L. A., Sweet, L. H., \& Munafò, M. R. (2011). Delayed reward discounting and addictive behavior: A meta-analysis. Psychopharmacology, 216(3), 305-321. https://doi.org/10.1007/s00213-

011-2229-0

Madden, M. (2014). Public perceptions of privacy and security in the post-Snowden era. Pew Research Center. https://www.pewresearch.org/internet/2014/11/12/public-privacy-perceptions/

Metzger, M. J. (2004). Privacy, trust, and disclosure: Exploring barriers to electronic commerce. Journal of Computer-Mediated Communication, 9(4), Article JCMC942. https://doi.org/10.1111/j.1083-6101.2004.tb00292.x

Metzger, M. J., \& Suh, J. J. (2017). Comparative optimism about privacy risks on Facebook. Journal of Communication, 67(2), 203-232. https://doi.org/10.1111/jcom.12290

Neff, G., \& Nafus, D. (2016). Self-tracking. The MIT Press.

Nicolaij, S., \& Hendrickx, L. C. W. P. (2003). The influence of temporal distance of negative consequences on the evaluation of environmental risks. In: L. Hendrickx, W. Jager, L. Steg (Eds). Human decision making and environmental perception. Understanding and assisting human decision making in real-life situations. University of Groningen.

O'Donoghue, T., \& Rabin, M. (1999). Doing it now or later. American Economic Review, 89(1), 103-124. https://doi.org/10.1257/aer.89.1.103

Petronio, S. (2002). Boundaries of privacy: Dialectics of disclosure. State University of New York Press.

Petronio, S. (2010). Communication privacy management theory: What do we know about family privacy regulation? Journal of Family Theory \& Review, 2(3), 175-196. https://doi.org/10.1111/j.1756-2589.2010.00052.x

Samuelson, P. A. (1937). A note on measurement of utility. The Review of Economic Studies, 4(2), 155-161. https://doi.org/10.2307/2967612

Sharot, T. (2011). The optimism bias. Current Biology, 21(23), R941-R945.

https://doi.org/10.1016/j.cub.2011.10.030

Shepperd, J. A., Carroll, P., Grace, J., \& Terry, M. (2002). Exploring the causes of comparative optimism. Psychologica Belgica, 42(1-2), 65-98. http://doi.org/10.5334/pb.986

Statistisches Bundesamt. (2016). 47 Millionen Menschen in Deutschland kaufen über das Internet ein [47 million people in Germany shop over the Internet]. https://www.destatis.de/DE/Presse/Pressemitteilungen/Zahl-derWoche/2016/PD16_28_p002.html;jsessionid=1ADCB676AD5B8ABA40764C9F25332996.cae2

Svenson, O., \& Karlsson, G. (1989). Decision-making, time horizons, and risk in the very long-term perspective. Risk Analysis, 9(3), 385-399. https://doi.org/10.1111/j.1539-6924.1989.tb01004.x

Sweeney, L. (2000). Simple demographics often identify people uniquely [Data Privacy Working Paper 3]. https://dataprivacylab.org/projects/identifiability/ 
Taddicken, M. (2014). The 'privacy paradox' in the social web: The impact of privacy concerns, individual characteristics, and the perceived social relevance on different forms of self-disclosure. Journal of ComputerMediated Communication, 19(2), 248-273. https://doi.org/10.1111/jcc4.12052

Teutsch, D., Masur, P. K., \& Trepte, S. (2018). Privacy in mediated and nonmediated interpersonal communication: How subjective concepts and situational perceptions influence behaviors. Social Media + Society, 4(2). https://doi.org/10.1177/2056305118767134

Thaler, R. H. (1981). Some empirical evidence on dynamic inconsistency. Economic Letters, 8(3), 201-207. https://doi.org/10.1016/0165-1765(81)90067-7

Trepte, S., Reinecke, L., Ellison, N. B., Quiring, O., Yao, M. Z., \& Ziegele, M. (2017). A cross-cultural perspective on the privacy calculus. Social Media + Society, 3(1). https://doi.org/10.1177/2056305116688035

Weinstein, N. D. (2000). Perceived probability, perceived severity, and health-protective behavior. Health Psychology, 19(1), 65-74. https://doi.org/10.1037/0278-6133.19.1.65

Weinstein, N. D., \& Klein, W. M. (1996). Unrealistic optimism: Present and future. Journal of Social and Clinical Psychology, 15(1), 1-8. https://doi.org/10.1521/jscp.1996.15.1.1

Westin, A. F. (1967). Privacy and freedom. Atheneum.

Whiteford, H. A., Degenhardt, L., Rehm, J., Baxter, A. J., Ferrari, A. J., Erskine, H. E., Charlson, F. J., Norman, R. E., Flaxman, A. D., Johns, N., Burstein, R., Murray, C. J. L., \& Vos, T. (2013). Global burden of disease attributable to mental and substance use disorders: Findings from the Global Burden of Disease Study 2010. The Lancet, 382(9904), 1575-1586. https://doi.org/10.1016/S0140-6736(13)61611-6

Wilson, D., \& Valacich, J. S. (2012). Unpacking the privacy paradox: Irrational decision-making within the privacy calculus. In ICIS 2012 Proceedings. AIS. https://aisel.aisnet.org/icis2012/proceedings/ResearchInProgress/101

\section{Appendices}

\section{Appendix A}

Figure 2. Respecified Path Model E-Commerce.

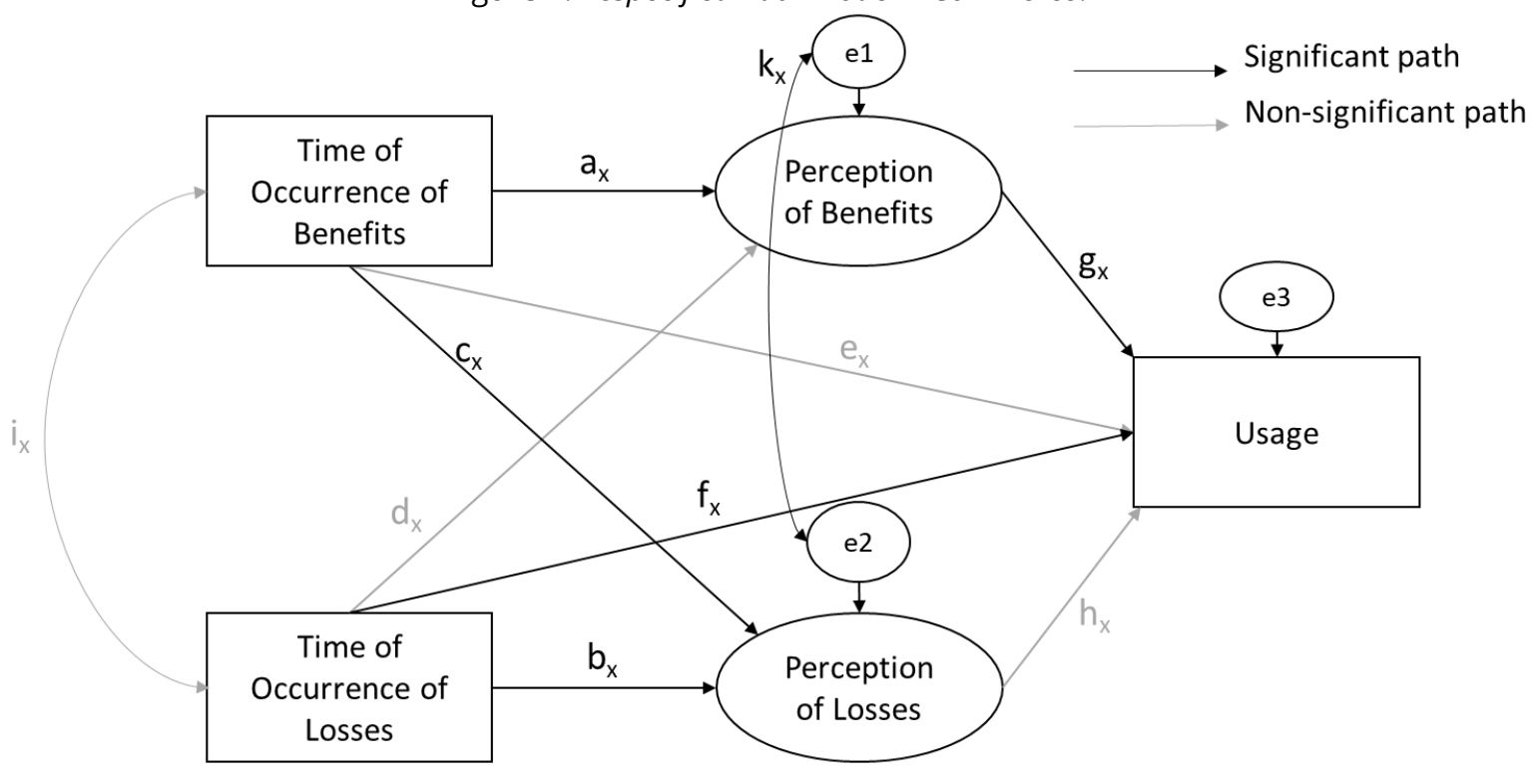


Figure 3. Respecified Path Model Political Online Participation.

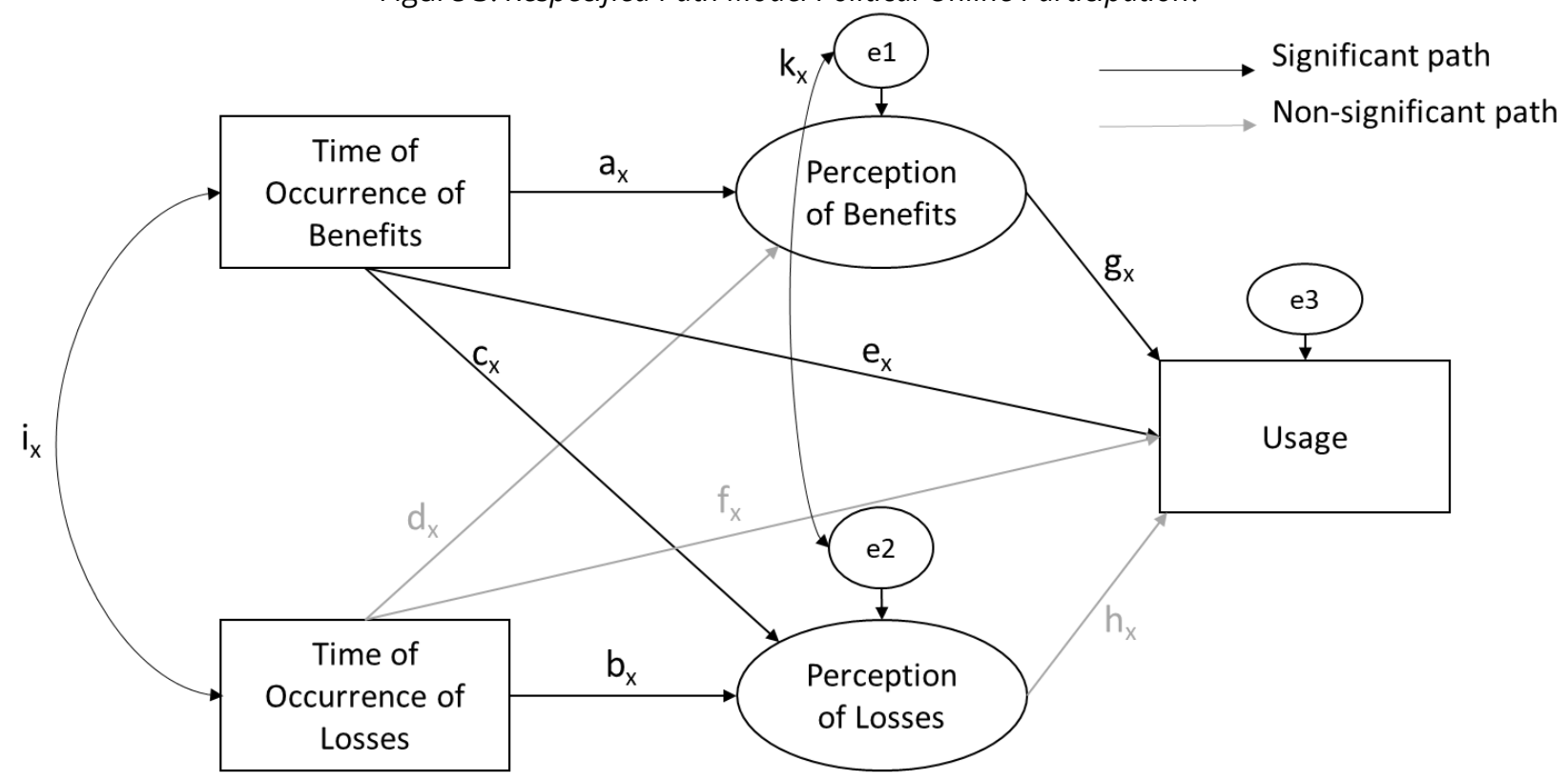

Figure 4. Respecified Path Model Self-Tracking.

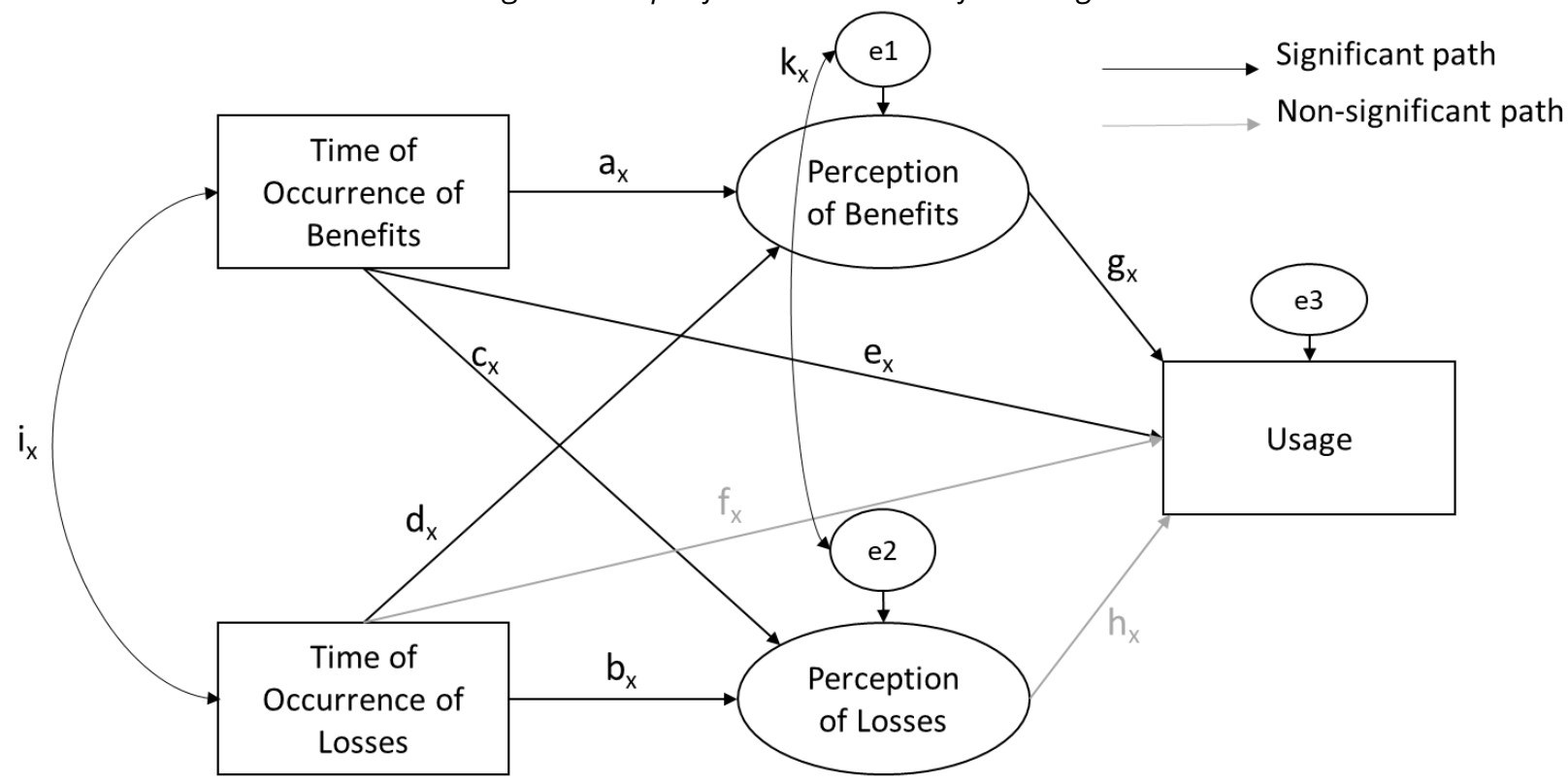


Table 3. Factorial Validity of Measurement Models and Indicators.

\begin{tabular}{|c|c|c|c|c|}
\hline Field of Activity & Variables \& Items-IDs & Factor loading $\lambda$ & Cronbach's a & AVE \\
\hline \multirow[t]{10}{*}{ E-commerce } & Perception of benefits & & .86 & .74 \\
\hline & Benefit1 & .887 & & \\
\hline & Benefit2 & .887 & & \\
\hline & Benefit3 & .800 & . & \\
\hline & Benefit4 & .858 & & \\
\hline & Perception of losses & & .92 & .61 \\
\hline & Losses1 & .826 & & \\
\hline & Losses2 & .652 & & \\
\hline & Losses3 & .844 & & \\
\hline & Losses4 & .787 & & \\
\hline \multirow[t]{10}{*}{ Political online participation } & Perception of benefits & & .95 & .84 \\
\hline & Benefit1 & .942 & & \\
\hline & Benefit2 & .937 & & \\
\hline & Benefit3 & .872 & & \\
\hline & Benefit4 & .912 & & \\
\hline & Perception of losses & & .91 & .71 \\
\hline & Losses1 & .877 & & \\
\hline & Losses2 & .748 & & \\
\hline & Losses3 & .862 & & \\
\hline & Losses4 & .874 & & \\
\hline \multirow[t]{10}{*}{ Self-tracking } & Perception of benefits & & .96 & .86 \\
\hline & Benefit1 & .939 & & \\
\hline & Benefit2 & .953 & & \\
\hline & Benefit3 & .903 & & \\
\hline & Benefit4 & .914 & & \\
\hline & Perception of losses & & .92 & .74 \\
\hline & Losses1 & .874 & & \\
\hline & Losses2 & .848 & & \\
\hline & Losses3 & .879 & & \\
\hline & Losses4 & .845 & & \\
\hline
\end{tabular}

Note. AVE = Average Variance Extracted.

Table 4. Matrix Implied Correlations E-Commerce.

\begin{tabular}{lcccc}
\hline & $\begin{array}{c}\text { Time of Occurrence of } \\
\text { Losses }\end{array}$ & $\begin{array}{c}\text { Time of Occurrence of } \\
\text { Benefits }\end{array}$ & $\begin{array}{c}\text { Perception of } \\
\text { Losses }\end{array}$ & $\begin{array}{c}\text { Perception of } \\
\text { Benefits }\end{array}$ \\
\hline $\begin{array}{l}\text { Time of Occurrence of } \\
\text { Losses }\end{array}$ & 1 & & & \\
Time of Occurrence of & -.040 & 1 & & 1 \\
Benefits & -236 & .198 & -.445 & 1 \\
Perception of Losses & .066 & -.348 & -.134 & .380 \\
Perception of Benefits & .127 & -.157 & & 1 \\
Usage & & & \\
\hline
\end{tabular}


Table 5. Matrix Implied Correlations Political Online Participation.

\begin{tabular}{lccccc}
\hline & $\begin{array}{c}\text { Time of Occurrence } \\
\text { of Losses }\end{array}$ & $\begin{array}{c}\text { Time of Occurrence } \\
\text { of Benefits }\end{array}$ & $\begin{array}{c}\text { Perception of } \\
\text { Losses }\end{array}$ & $\begin{array}{c}\text { Perception of } \\
\text { Benefits }\end{array}$ & Usage \\
\hline $\begin{array}{l}\text { Time of Occurrence } \\
\text { of Losses }\end{array}$ & 1 & & & & \\
Time of Occurrence & .267 & 1 & & \\
of Benefits & -.190 & .066 & 1 & 1 \\
$\begin{array}{l}\text { Perception of Losses } \\
\text { Perception of }\end{array}$ & -.049 & -.389 & -.178 & .456 & 1 \\
$\begin{array}{l}\text { Benefits } \\
\text { Usage }\end{array}$ & -.111 & -.306 & -.069 & & \\
\hline
\end{tabular}

Table 6. Matrix Implied Correlations Self-Tracking.

\begin{tabular}{lccccc}
\hline & $\begin{array}{c}\text { Time of Occurrence } \\
\text { of Losses }\end{array}$ & $\begin{array}{c}\text { Time of Occurrence } \\
\text { of Benefits }\end{array}$ & $\begin{array}{c}\text { Perception of } \\
\text { Losses }\end{array}$ & $\begin{array}{c}\text { Perception of } \\
\text { Benefits }\end{array}$ & Usage \\
\hline $\begin{array}{l}\text { Time of Occurrence } \\
\text { of Losses }\end{array}$ & 1 & & & & \\
Time of Occurrence & .173 & 1 & & \\
of Benefits & -.244 & .240 & 1 & 1 \\
$\begin{array}{l}\text { Perception of Losses } \\
\text { Perception of }\end{array}$ & .127 & -.424 & -.400 & .388 & 1 \\
$\begin{array}{l}\text { Benefits } \\
\text { Usage }\end{array}$ & .011 & -.298 & -.187 & \\
\hline
\end{tabular}

\section{Appendix B}

List 1. Question Items for All Variables - English version

\section{English version Question Item}

\section{E-commerce - Usage Behavior (DV)}

"Could you please try to estimate what percentage of your total private purchases you are making on the Internet today?"

\section{Political Online Participation - Usage Behavior (DV)}

All items could be answered with "Yes/No/Do not know"

"In the last 12 months, have you used the Internet (or Internet-based applications) ..."

“... to follow online discussions between politicians and other users?"

“... to receive political newsletters?"

“... to participate in political discussions?"

“... to write a politician directly (for example, by e-mail, Facebook, Twitter or [country specific website])?"

“... to write political comments?"

“... to send a political message via e-mail to friends, acquaintances or colleagues?"

“... to support a petition?"

“... forward a political message, a political video or a political link?"

“... to draw attention to political events in social networks?"

“... to get advice from an application like the [country specific voting advice platform]?"

"... to get informed, discuss or participate online?"

\section{Self-Tracking - Usage Behavior (DV)}

All items could be answered with "Yes/No/Do not know" 
"Have you used the Internet (or Internet-based applications) in the past 12 months to ..."

"... to measure your daily pace?"

"... to control your food intake?"

“... to track your sleep and / or wake-up times?"

“... to control your personal performance in sports?"

“... to track your covered distances?"

“... have health-related data checked by a doctor?"

“... to control your personal performance while learning or at work?"

“... to document your mood or state of mind?"

“... to control your calorie consumption?"

“... to document your physical health?"

“... to check if you reach your personal goals?"

“... otherwise automatically record information about your sports activities, habits and health status?"

\section{Perception of Benefits/Losses}

\section{Introduction to Benefits/Losses Scale}

Nowadays, many everyday activities are done online, such as shopping, reading the newspaper or exchanging news. These developments are assessed differently. What about you, to what extent do you agree or disagree with the following statements (regardless of whether and how intensively you use the described possibilities yourself)?

Preface - E-Commerce

"The fact that I can shop online and / or use customer cards from shops and service providers, ..."

Preface - Political Online Participation

"The fact that I can inform myself politically on the Internet, express my opinion and participate politically, ..."

Preface - Self-Tracking

"The fact that I can use digital technology to automatically record information about my sports activities, habits and health status (so-called self-tracking), ..."

... is useful for me. (Benefit1)

... is an advantage for me. (Benefit2)

... has positive effects for me. (Benefit3)

... is a win for me. (Benefit4)

... is risky for me. (Losses 1 )

... is a disadvantage for me. (Losses2)

... is dangerous for me. (Losses3)

... is harmful to me. (Losses4)

\section{Perceived occurrence of benefits and losses}

All items were measured on a 7-point scale ranging from (1) 'today' to (7) 'far away future'; alternative option 'never' Preface - E-Commerce

"At the beginning of this questionnaire, we asked you if it was harmful or useful for you to shop online."

Preface - Political Online Participation

"At the beginning of this questionnaire, we asked you if it was harmful or useful to you, that you could use the Internet to inform yourself about political matters, express your opinion, and participate politically."

Preface - Self-Tracking

"At the beginning of this questionnaire, we asked you if it was harmful or useful for you to use digital technology to automatically record information about your sports activities, habits and health status."

Final Question (Benefits):

"What would you say, when - if at all - does the benefit occur to you?"

Final Question (Damages):

"What would you say, when - if at all - does the damage occur to you?" 


\section{Correspondence to:}

Marco Lünich

Institute of Social Sciences

Heinrich Heine University Düsseldorf

Universitätsstraße 1

40225 Düsseldorf

Germany

Email: marco.luenich(at)hhu.de

Editorial record: First submission received on January 23, 2020. Revisions received on July 9, 2020, February 5, 2021 and April 30, 2021. Accepted for publication on June 2, 2021.

Editor in charge: Alexander Schouten

\section{About Authors}

Marco Lünich is a postdoctoral researcher at the Institute for Social Sciences at Heinrich Heine University Düsseldorf, Germany. His research and teaching areas include political communication and the public perceptions of Big Data and Artificial Intelligence.

Frank Marcinkowski is a full professor for communication science at the Institute for Social Sciences at Heinrich Heine University Düsseldorf, Germany. His research and teaching areas include communication theories, political communication, and online media.

Kimon Kieslich is a PhD student at the Institute of Social Sciences at Heinrich Heine University Düsseldorf, Germany. His research interests lie in public opinion on digital media as well as political communication.

(C) Author(s). The articles in Cyberpsychology: Journal of Psychosocial Research on Cyberspace are open access articles licensed under the terms of the Creative Commons BY-NC-ND 4.0 International License which permits unrestricted, non-commercial use, distribution and reproduction in any medium, provided the work is properly cited. 